\title{
Frédéric Thomas, Rimbaud Révolution
}

\section{Mario Richter}

\section{(2) OpenEdition}

\section{Journals}

\section{Edizione digitale}

URL: https://journals.openedition.org/studifrancesi/21566

DOI: 10.4000/studifrancesi.21566

ISSN: 2427-5856

\section{Editore}

Rosenberg \& Sellier

\section{Edizione cartacea}

Data di pubblicazione: 1 décembre 2019

Paginazione: 598

ISSN: 0039-2944

\section{Notizia bibliografica digitale}

Mario Richter, «Frédéric Thomas, Rimbaud Révolution», Studi Francesi [Online], 189 (LXIII | III) | 2019,

online dal 01 mars 2020, consultato il 11 novembre 2021. URL: http://journals.openedition.org/ studifrancesi/21566 ; DOI: https://doi.org/10.4000/studifrancesi.21566

\section{Questo documento è stato generato automaticamente il 11 novembre 2021.}

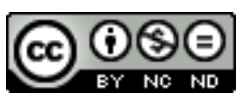

Studi Francesi è distribuita con Licenza Creative Commons Attribuzione - Non commerciale - Non opere derivate 4.0 Internazionale. 


\title{
Frédéric Thomas, Rimbaud Révolution
}

\author{
Mario Richter
}

\section{NOTIZIA}

Frédéric Thomas, Rimbaud Révolution, Paris, L'échappée, 2019, 103 pp.

1 Caratterizzato dai risentiti accenti del pamphlet antiborghese e anticapitalistico, questo agile libro consente di seguire un percorso storico-letterario denso e significativo. Prende avvio dall'evento della Comune e dei proscritti di Bruxelles e Londra per addentrarsi nei temi e nelle visioni rivoluzionarie, simili e diverse, di Marx e di Rimbaud, con lo scopo di giungere al novecentesco tentativo di sintesi e di sviluppo che ha dato il principale senso al movimento collettivo del Surrealismo, la cui principale istanza è appunto consistita nel cercare di combinare le ben note parole d'ordine di Marx e Rimbaud, rispettivamente «trasformare il mondo» e «cambiare la vita». Il rischio di un simile approccio, che tra l'altro riprende una vicenda storiografica da tempo variamente frequentata e raccontata, poteva certo consistere in un discorso impoverito da una generica banalità. In realtà, Frédéric Thomas ha saputo conferire alla sua argomentazione una passione ideologica guidata da un'osservazione oggettiva dei fatti, sostenuta da una conoscenza precisa degli autori presi in considerazione, soprattutto avvalendosi, per quanto riguarda Rimbaud, degli attenti e informati studi di Steve Murphy. Con probanti argomenti e calzanti esempi si dimostra che «ce n'est [...] ni du côté du passé ni du côté de l'utopie que Marx et Rimbaud cherchent les chances de salut, mais dans l'immanence d'un ici et maintenant, chargé de la mémoire du passé et des rêves utopiques» (p. 39). Per quanto poi riguarda l'esito del Surrealismo, sono messe bene in luce le ragioni che non hanno consentito al movimento di confondersi integralmente con i partiti comunisti, compromessi con la degenerazione della rivoluzione russa e del suo capo. Così l'A. conclude nell'«Épilogue»: «Nous sommes loin d'être venus à bout de la défaite du surréalisme, du silence de Rimbaud; ils durent encore, brûlent encore jusqu'à nous, projetant sur toutes "nos" victoires l'ombre langoureuse du "tremble carcasse"» (p. 96). Il principale valore di questo libro risiede nella chiara e contenuta passione ideologica che orienta il suo autore attraverso una 
conoscenza precisa degli autori presi in esame e grazie anche a una limpida e avvolgente esposizione. 